\title{
An evaluation model of water-saving reconstruction projects based on resource value flows
}

(C) The Author(s) 2020. This article is published with open access at link.springer.com and journal.hep.com.cn

\begin{abstract}
Due to uncertainties in water supply, there is growing demand for water resource management in enterprises. In this study, we evaluated the effects of companies' water-saving reconstruction projects. We used Hina Advanced Materials Company as a case to construct an investment decision model to (1) calculate the internal and external costs of water resources based on circular economic value analysis theory, and (2) locate the level of water resources circulation. We adopted gray situation decision analysis to identify the typical problems that occur in water resource utilization. Moreover, we demonstrated optimization plans for different potential improvements, thereby providing guidance and references for water resource cost management and the comprehensive optimization of environmental benefits. We concluded that the circulation economic value analysis model can effectively display the flow and amount of value derived from water resource flows, thereby providing guidance and suggestions for optimizing water resource flows.
\end{abstract}

Received February 28, 2020; accepted August 7, 2020

Runwen JIANG, Lingchu ZHAO

Central South University, Changsha 410083, China

\section{Xiaohong CHEN}

Collaborative Innovation Center of Resource-conserving \& Environment-friendly Society and Ecological Civilization, Central South University, Changsha 410083, China; Mobile E-business 2011 Collaborative Innovation Center of Hunan Province, Hunan University of Technology and Business, Changsha 410205, China

Zhifang ZHOU

Collaborative Innovation Center of Resource-conserving \& Environment-friendly Society and Ecological Civilization, Central South University, Changsha 410083, China

Tao ZHANG ( $₫)$

Loughborough University London, London E20 3BS, UK

E-mail: t.n.zhang@1boro.ac.uk

This research was supported by the projects of the National Social Funds of China (Grant No. 18BJY085).
Keywords value flow analysis, ternary materials enterprises, grey situation decision analysis, water resources

\section{Introduction}

Nearly half of China's water resources are substantially polluted as urbanization accelerates and industrial sewage is discharged irresponsibly. Some serious water pollution events, such as the contamination of Songhua River with benzene, algae water pollution in Taihu Lake, and Jingjiang water pollution, have caused adverse social impact and immense economic losses, which significantly threatens the sustainable development of society and the daily life of residents. The ternary materials industry has received widespread attention from the public due to the massive amount of wastewater discharged from its production processes which results in significant environmental pollution. This industry has a water consumption of 10 tons per ton of product and a low utilization rate of water recycling. Moreover, a large amount of wastewater containing heavy metals, salt, and ammonia is produced by this industry. The average emission of chemical oxygen, which is the most harmful indicator of environmental pollution in wastewater, is $150 \mathrm{mg} / \mathrm{L}$. Evidently, the production and operation activities of the ternary materials industry cause severe environmental pollution and resource consumption, and its impact on the natural environment is similar to that of traditional high-pollution industries, such as iron and textiles. With the continuously increasing conflict between the supply and demand of water resources, this industry is facing several urgent problems: Poor water resource management; various threats, such as population growth, urbanization, climate change, and pollution; and aggravation of the disadvantages of the traditional water resource management system (Collet et al., 2015; Giuliani, 2016). Therefore, the demand for effective water management for the companies in this industry is increasing (Park et al., 2013; Signori and Bodino, 2013). However, extant studies disregard the 
important role of environmental management accounting in this field (Christ and Burritt, 2017). Research focusing on optimizing enterprise production from the aspects of theoretical construction and technological innovation to achieve energy conservation and emission reduction is thus required (Ding et al., 2018).

Environmental management accounting was developed in the 1990s. Managers began to realize the need to incorporate environmental impact into their economic decision-making processes. Many of them have successfully applied environmental management accounting to the low-carbon emissions research of enterprises (Burritt et al., 2011). However, water resources as an important component of natural resources have received little attention in environmental management research. Currently, the standard method widely recognized by the research community is material flow cost accounting (MFCA) ${ }^{1)}$. In the current context of a circular economy, the application of MFCA has often led companies to experience a "circulatory diseconomy", and this method does not reflect "externalities" (Xiao and Jin, 2008). Resource value circulation accounting is a branch of accounting that considers the background of a circular economy. Through the accounting and diagnosis of the "material flow-value flow" of enterprises, the potential points for improvement are discovered, and an optimal decisionmaking scheme is analyzed to solve the problems in the circulation of enterprises. Material flow-value flow is a good complement to the existing cost accounting system; it helps overcome the difficulty of identifying the external damage value of waste discharge included in the product manufacturing cost figures, and track feedback to analyze the value flow information before and after the implementation of the circular economy (Zhou and Liu, 2017). Therefore, in this study we attempt to optimize the ternary materials industry using water resource value flow analysis to improve the economic benefits of water resources. This research bridges the application gap of resource value flow in the field of water resources management and provides suggestions for enterprises to open up the sources and regulate the flows with practical significance.

The remainder of this paper is organized as follows. Section 2 reviews the relevant literature on resource value circulation accounting, water resources accounting, and water disclosure. Section 3 applies cyclic economic value analysis method, analytic hierarchical process (AHP), and gray situation decision-making to construct the ternary materials industry water resources value circulation accounting model, evaluation, and decision system. Section 4 uses the Hina Advanced Materials Company as a case to calculate the water resource value flow, and uses the aforementioned evaluation and decision-making system to select the optimal program. Lastly, Section 5 summarizes the study.

\section{Literature review}

\subsection{Resource value flow accounting}

In recent years, many scholars have begun to use MFCA to analyze the relative costs of enterprises (Nakajima et al., 2015; Sulong et al., 2015). Specialized research has been conducted on eco-industrial parks and on the issue of material flow circulation in society from the recycling industry perspective (Prox, 2015; Wan et al., 2015; Xiao et al., 2017). At the corporate level, scholars have often used MFCA to calculate and analyze the relevant costs of companies to identify key improvements in their production processes and reduce their consumption of goods and production costs (Herzig et al., 2013).

Resource value flow accounting is an extension of MFCA in the context of a circular economy (Xiao and Liu, 2014; Xiong and Xiao, 2014; Xiong et al., 2015), forming a binary cost accounting system. The related research can be divided into three major categories. (1) System Construction. This category analyzes the material flow, element flow, and resulting value flow in the production processes in the context of a circular economy (Xiao and Liu, 2014). (2) Extended Research. These studies analyze the vertical expansion based on the calculation results of corporate resource value flow (e.g., Live Intrinsic Material Estimation (LIME) evaluation system of resource value circulation, evaluation systems based on AHP, and gray situation decision-making) (Xiao and Xiong, 2010; Zheng and Xiao, 2010). (3) Practical Application. This system standard is applied comprehensively across enterprises, enterprise groups, and industrial parks to test and improve theoretical systems in practice. Overall, the academic community has made immense progress studying heavy industries, such as coal and iron manufacturing, using cost accounting and environmental benefit assessment case studies that are based on resource value flow (Busch et al., 2005; Jasch, 2008). Water resources, as a special research object, can be regarded as a medium of energy, similar to such resources as coal and gas. However, extant literature has mainly evaluated the use of water resources based on MFCA evaluation models (Gao et al., 2016) and has not addressed water resources from the perspective of resource value flow accounting.

\subsection{Water accounting}

Water is a shared resource and its usage will impact all users. Therefore, governments, communities, and

1) ISO 14051:2011. Environmental management: Material flow cost accounting - General framework. Available at: iso.org/standard/50986.html 
companies must be responsible for their use of water resources (Chapagain and Tickner, 2012). Companies are the main consumers of fresh water resources (Jones et al., 2015), thereby necessitating that they assume water-related responsibilities and develop the related resource strategies (Hazelton, 2014; Martinez, 2015). Such strategies must consider various risks related to water usage, including financial, operational, product, reputation, and regulatory risks. The use of water accounting can effectively reduce these risks (Burritt et al., 2016; Cassimon et al., 2016). Accurate water accounting is an important component of cleaner corporate production. It can help companies determine the ecological impact of direct and indirect water emissions and assess corporate water risks, thereby allowing companies to properly report development trends and water usage impact to its stakeholders (Li et al., 2016). At present, water accounting is still evolving (Chapagain and Tickner, 2012). Some studies have analyzed the value accounting of water resources (Gao et al., 2016), but many companies continue to rely on incomplete data to make economic decisions on water resources. This situation is partially caused by lack of corporate water disclosure mechanisms. In response to this problem, empirical and case studies have been conducted on water information disclosure (Burritt et al., 2016; Qiu et al., 2016). However, understanding how to effectively use water information data for economic decision-making will become a concern, particularly with the deepening of the water disclosure research.

WBCSD-SIUCN proposed five stages of water resource management to enable managers understand the interaction of accounting tools in the analysis of water resources, and the corresponding steps they may follow (Christ and Burritt, 2017). Therefore, resource value transfer accounting can considerably meet the requirements of water resource management and help enterprises achieve circular economic management of water resource using resource value transfer accounting. Common methods that can be used for water resources efficiency evaluation and decision-making include fuzzy comprehensive evaluation, AHP, data envelopment analysis (DEA) efficiency evaluation analysis, and gray situation decision analysis. Among them, the membership function of each factor should be determined using fuzzy comprehensive evaluation, given that the practicality of applying this method is insufficient. The DEA efficiency evaluation analysis is based on relative efficiency and cannot directly reflect the objective level of decision-making units, which are subject to extreme values. However, the AHP is simple and easy to understand, and combines qualitative and quantitative analyses to enable systematic evaluation and decisionmaking. Accordingly, decision makers can easily master this process. The gray situation decision analysis mainly uses completely determined information to address incomplete information, and is suitable for the optimization problem of multi-objective projects (Pitchipoo et al.,
2013). Water resource management needs to comprehensively consider various objectives, such as the economy, environment and resources. Meanwhile, the gray situation decision analysis uses deterministic information to address uncertain events and quantifies the incomparable indicators to choose between the optimal solutions. By contrast, other analysis methods cannot fully deal with various sudden uncertainties and generate major risks. The key of the gray situation decision analysis is to determine the target system and polarity of each target. A model should be introduced to determine the weight of each target owing to the inconsistency of each target. Furthermore, the characteristics of resource value flow and water information data limit the application of objective weighting methods, such as entropy weighting and coefficient of variation methods. By contrast, AHP is concise and practical, can deal with some data that cannot be measured quantitatively, and can reflect the real purpose of evaluation. Overall, the current study combines AHP with the gray situation decisionmaking method (Çelikbilek and Tüysüz, 2016; Bouzon et al., 2018).

In summary, many studies on water resource management have been conducted, but the research has generally remained at the theoretical framework and/or material circulation level. Research on water resource value flow has yet to be accomplished, and the application of environmental management accounting to water accounting has not been taken seriously. The current study used the calculation of the water resource value flow in the ternary materials industry as bases to propose a selection plan, and utilized AHP and gray situation decision-making to optimize the water resources of the case company.

\section{Water resource value flow evaluation models}

After water resources enter companies, their material forms gradually flow along with the production process. Except for an extremely small amount of water resources that reverts back to nature, other substances become new forms of water resources to be exported (i.e., products or wastes). This study combined the principle of vertical resource flow and the gradual carry-over processing method, and set the basic principle of the value flow analysis of water resources as a binary two-way structural model. The first element (i.e., fundamental element) refers to water resources material flow that corresponds with material flow analysis. The second element (i.e., derived element) refers to the value cycle of water resources and corresponds to the value flow analysis of water resources.

\subsection{Water resource value flow calculation model}

We used the internal resource value flow calculating model (1) to enable the positive product cost (i.e., effective use 
value of resource circulation) and negative product cost (i.e., the value of resource flow loss) of enterprises to be calculated to measure the internal loss of resources in their production processes. We used the external environmental damage value accounting model (i.e., LIME method) to statistically derive the external environmental cost of companies' resource consumption and pollutant emissions to provide a basis for production decision-making and environmental management.

The new investment cost of the volume center

+ The transfer cost of the front volume

$=$ Cumulative input cost,

$$
\begin{aligned}
& \sum_{j=1}^{J} \sum_{i=1}^{I} s_{i} \times D F_{i j} \times W T P_{j} \\
& =\sum_{i=1}^{I} s_{i} \times\left(\sum_{j=1}^{J} D F_{i j} \times W T P_{j}\right),
\end{aligned}
$$

where $s_{i}$ indicates the life cycle list of substance $i, D F_{i j}$ represents the damage coefficient of substance $i$ to protective object $j$, and $W T P_{j}$ represents the amount of damage avoidance that $j$ is willing to pay for each $i$-metric unit.

To strengthen the management of corporate resource value flow and effectively reduce waste and the consumption of resources, internal losses should be assessed and the impact of production on the environment must be measured. This study combined the value of negative product loss with that of external environmental damage to form a complete two-dimensional accounting and diagnosis model for resource flow. This model constitutes a two-dimensional analysis framework and evaluation theory of "internal loss of resource-external environmental damage to waste".

\subsection{Water resource value flow evaluation model}

The analysis of water resource value flow evaluation is extremely important and has the function of linking with other types of analysis. The commonly used methods are AHP, eco-efficiency assessment method, and DEA efficiency evaluation analysis method. The current research analyzed the value flow of water resources comprehensively. Therefore, AHP was used (Khalil et al., 2016; Sindhu et al., 2017).

In the process of constructing our model, the current study referred to scholars' methods for constructing value flow indicators according to the basic characteristics of resource input, recycling and output links, and availability of enterprise data (Hu et al., 2014; Zhou et al., 2018). Moreover, the evaluation index system was divided into target, criterion, and index layers. Thereafter, we referred to scholars who have adopted expert consultation method to evaluate the comparative value of the importance of evaluation indicators at all levels (Yang, 2006; Song and Li, 2012). For example, the indicators of the criterion layer include water input $(\mathrm{C} 1)$, water recycling $(\mathrm{C} 2)$, and water output $(\mathrm{C} 3)$. The criterion layer establishes the judgment matrix according to the professional:

$A=\left[\begin{array}{lll}1 & 2 & 1 \\ 1 / 2 & 1 & 1 \\ 1 & 1 & 1\end{array}\right]$.

First, we found the weight of the indicator system $W_{i}=$ $(0.413,0.260,0.327)$.

Second, we determined the largest eigenvalue of the judgment matrix as follows: $\lambda_{\max }=3.0536, C I=\left(\lambda_{\max }-n\right) /$ $(n-1)=(3.0536-3) / 2=0.0268$.

If $n=3$, then we checked the table to find that $R I=0.52$. Thus, $C R=C I / R I=0.0515<0.1$.

Note that the judgment matrix had relatively satisfactory consistency, and the distribution of weights was reasonable. We used the same method to judge other indicators, and we obtained the weight coefficient of the three indexes to the two indexes of the evaluation index system (Table 1). Furthermore, we referred to the Cleaner Production Guidelines of the ternary materials industry, and combined the brainstorming method thereafter with the expert scoring method to determine the resource flow efficiency evaluation level (see Table 2).

\subsection{Control of water resource value flow}

\subsubsection{Model construction}

The comprehensive evaluation and diagnosis of the cost analysis results of the enterprise value flow is the basis for decision-making optimization. This study integrated the existing literature (Çelikbilek and Tüysüz, 2016; Wei, 2017; Bouzon et al., 2018) with the industry characteristics, and used the gray relational method to build a circular economic optimization model and draw a complete evaluation index system according to the judgment score from the application level (Table 3). Table 3 further illustrates and progresses the indicator system shown in Table 1.

\subsubsection{Decision optimization implementation}

Combined with the extended optimization model that we constructed, the decision-making and optimal design of the circular economy value flow of the ternary materials industry could be made in accordance with the basic flow of the gray situation decision-making. The gray situation decision model has four basic elements: Situations, countermeasures, targets, and effects. 
Table 1 Quantitative index system for water resource value flow evaluation in the ternary materials industry

\begin{tabular}{|c|c|c|c|c|}
\hline Goal layer & Criterion layer & Weight & Index layers & Weight \\
\hline \multirow{13}{*}{$\begin{array}{l}\text { Water resource } \\
\text { value flow } \\
\text { evaluation } \\
\text { index }(\mathrm{H})\end{array}$} & \multirow[t]{4}{*}{ Water input (C1) } & \multirow[t]{4}{*}{0.413} & Sales water cost rate & 0.462 \\
\hline & & & Fresh water consumption per unit product & 0.203 \\
\hline & & & Cycle water consumption per unit product & 0.203 \\
\hline & & & Wastewater treatment cost per unit product & 0.132 \\
\hline & \multirow[t]{4}{*}{ Water recycling $(\mathrm{C} 2)$} & \multirow[t]{4}{*}{0.260} & Water resource cost loss rate & 0.388 \\
\hline & & & Water recycling rate & 0.214 \\
\hline & & & Ratio of internal resource value to external environmental damage & 0.274 \\
\hline & & & Ammonia wastewater treatment rate & 0.124 \\
\hline & \multirow[t]{5}{*}{ Water output (C3) } & \multirow[t]{5}{*}{0.327} & Ammonia emissions per unit product & 0.218 \\
\hline & & & Ammonia wastewater discharge per unit product & 0.380 \\
\hline & & & Chemical oxygen demand emissions per unit product & 0.152 \\
\hline & & & External damage value per unit product & 0.175 \\
\hline & & & Total nitrogen emissions per unit product & 0.075 \\
\hline
\end{tabular}

Table 2 Ternary materials industry resource flow efficiency evaluation level

\begin{tabular}{lcc}
\hline Resource flow efficiency level & Comprehensive evaluation score & Resource flow efficiency \\
\hline I & 0.80 to 1.00 & Consistent with international advanced standards \\
II & 0.60 to 0.80 & Consistent with domestic advanced standards \\
III & 0.40 to 0.60 & Met the basic domestic standards \\
IV & Below 0.40 & Failed to meet basic domestic standards \\
\hline
\end{tabular}

Table 3 Optimization of water resource value flow index and weight allocation in ternary materials industry

\begin{tabular}{|c|c|c|c|}
\hline Validity index & Specific indicators & Weight & Extremum \\
\hline \multirow{4}{*}{$\begin{array}{l}\text { Comprehensive economic } \\
\text { utility indicators A }\end{array}$} & A1: Total investment & 0.0893 & Minimal \\
\hline & A2: Economic benefits & 0.0954 & Maximal \\
\hline & A3: Annual operating cost & 0.0659 & Minimal \\
\hline & A4: Added value output efficiency & 0.0686 & Maximal \\
\hline \multirow[t]{4}{*}{ Resource flow indicators B } & B1: Water resource cost loss rate & 0.0995 & Minimal \\
\hline & $\mathrm{B} 2$ : Water recycling rate & 0.0680 & Maximal \\
\hline & B3: Change rate of wastewater treatment cost & 0.0955 & Minimal \\
\hline & B4: Change rate of internal resource value flow & 0.1246 & Minimal \\
\hline \multirow{4}{*}{$\begin{array}{l}\text { Social environmental } \\
\text { benefit indicators C }\end{array}$} & $\mathrm{C} 1$ : Change rate of ammonia nitride emissions & 0.1182 & Minimal \\
\hline & C2: Change rate of exhaust gas damage value & 0.0304 & Minimal \\
\hline & C3: Change rate of external damage per unit output & 0.0593 & Minimal \\
\hline & C4: Change rate of wastewater discharge & 0.0752 & Minimal \\
\hline
\end{tabular}

(1) Build the situation

Only one event is involved in the decision-making process for water resource value flow in the ternary materials industry: Optimizing project investment marked as $a_{1}$, where $b_{j}(j=1,2, \ldots, n)$ is the $j$ th decision of the corresponding event $a_{1}$. The combination of $b_{j}$ and $a_{1}$ is the situation $S_{1 j}=\left(a_{1}, b_{j}\right)=$ (event, countermeasure), and the situations constitute a situation set $S=\left\{S_{1 j}=\left(a_{1}, b_{j}\right)\right\}$.

(2) Provide targets and their polarity

The target is a measurement of how good the situation is, and the number of targets for multi-objective decisionmaking is generally above 1 . The polarity of the target is a requirement for the magnitude of the sample effect, which is divided into three types: "maximal", "minimal", and "moderate". The calculation method for measuring the effects of different polarity targets is also different from one another. Table 3 provides the details.

(3) Assign effect samples to different targets

The essence of the effect samples is to determine the effects of situations. The effect sample of the qualitative 
target is obtained by expert scoring or from the experience of the enterprise management. Moreover, the effect sample of the quantitative index can be obtained through the budget of the solution. In particular, $E_{i j}^{P}$ is the effect sample of $S_{i j}$ at target $P$ and $E$ is the effect sample matrix for all targets.

$$
E=\left[\begin{array}{llll}
E_{11}^{P} & E_{12}^{P} & \cdots & E_{1 n}^{P} \\
E_{21}^{P} & E_{22}^{P} & \cdots & E_{2 n}^{P} \\
\vdots & \vdots & \vdots & \vdots \\
E_{m 1}^{P} & E_{m 2}^{P} & \cdots & E_{m n}^{P}
\end{array}\right] .
$$

(4) Calculate the effect measure for targets of different polarities

The effect measure of the "maximal" target:

$$
R_{i j}^{P}=\frac{E_{i j}^{P}}{\max E_{i j}^{P}}\left(0 \leqslant R_{i j}^{P} \leqslant 1\right) .
$$

The effect measure of the "minimal" target:

$$
R_{i j}^{P}=\frac{\min E_{i j}^{P}}{E_{i j}^{P}}\left(0 \leqslant R_{i j}^{P} \leqslant 1\right) .
$$

The effect measure of the "moderate" target:

$$
R_{i j}^{P}=\frac{\min E_{i j}^{P}}{\max E_{i j}^{P}}\left(0 \leqslant R_{i j}^{P} \leqslant 1\right) .
$$

(5) Calculate comprehensive performance measures and make optimal decisions

According to the weight of each target, a comprehensive measure of effectiveness can be obtained.

$$
R_{i j}^{\Sigma}=\sum_{P=1}^{k} W_{P} \times R_{i j}^{P} \quad\left(W_{P} \text { is the weight of } P\right.
$$

$k$ is the target number, $P=1,2, \ldots, k)$.

\section{Case analysis: Hina Advanced Materials Co., Ltd.}

\subsection{Background}

Hina Advanced Materials Co., Ltd. was established on September 10, 2003 in the Ningxiang Economic and Technological Development Zone, Hunan Province. This company is an integrated supplier of positive electrode precursor materials and related products for lithium ion batteries. It is a representative enterprise in ternary material industry. According to the characteristics of Hina shown in Fig. 1, the production process is divided into three stages: Synthesis reaction, water filtration, and dry sieving. Two types of wastewater are discharged during the production process: One is ammonia-containing wastewater, while the other is precipitated water that cannot be treated with ammonia during the precipitation process. The water resources cycle process in Hina is relatively complex. Accordingly, some data cannot be measured quantitatively and the target value of water resource transfer is difficult to define. Therefore, the model in this study is more suitable than the objective weighting model.

\subsection{Calculation of Hina's water resource value flow}

Hina converts resources into positive and negative

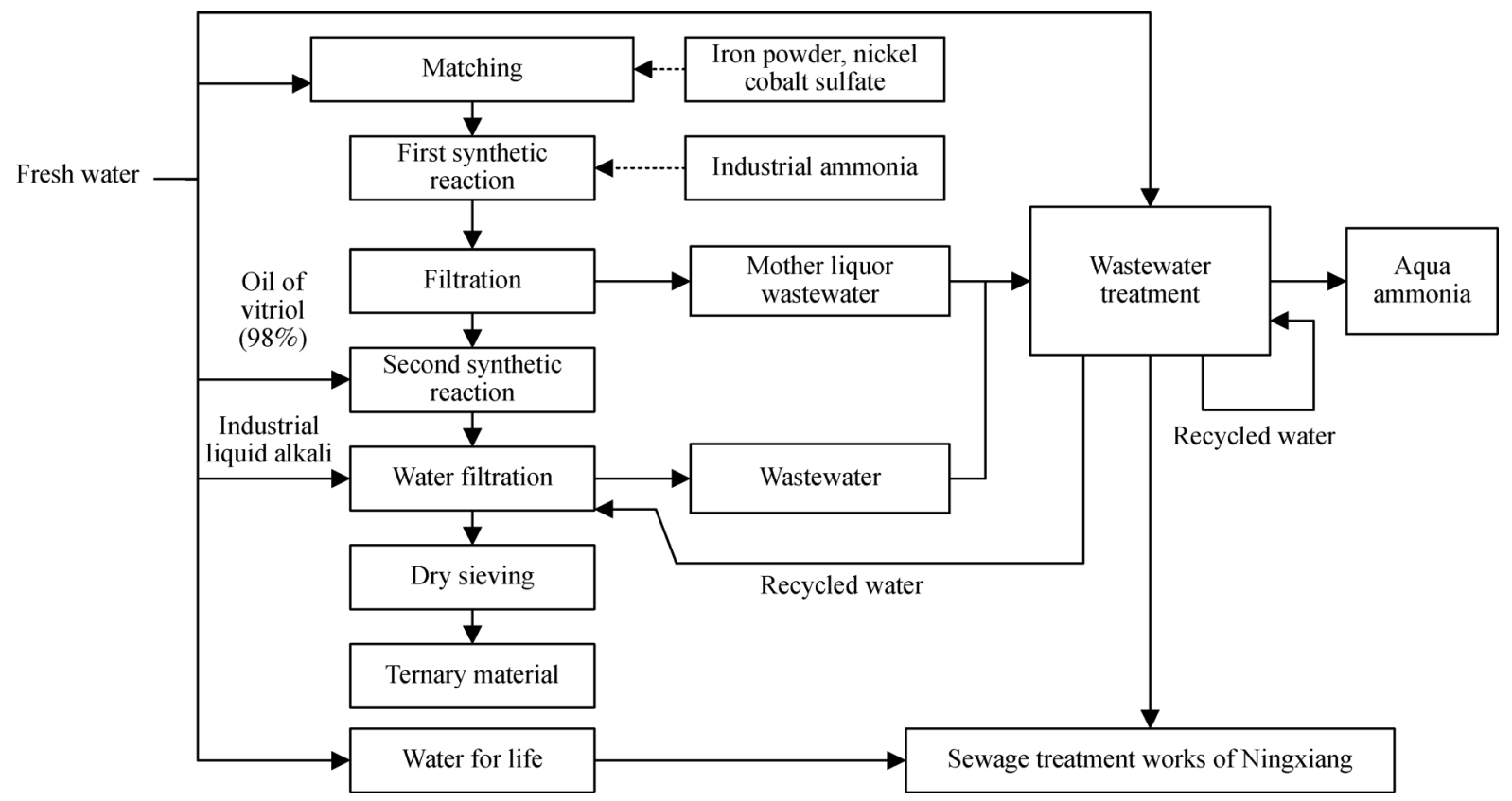

Fig. 1 Water resource transfer balance graph of Hina. 
products through its production processes. Positive products are sold to form the total industrial output value of the company. By contrast, negative products, such as washing slag, are discharged into the environment. We can calculate the internal costs of positive and negative products based on the input and output data of the company's water resources. The various wastewater, exhaust gas, and waste residues generated by the company in the production process will inevitably produce a corresponding external effect on the natural environment. We combined the value of the negative product losses in the company's internal production with the value of its external environmental damage (Table 4).

Note that the internal resource flow and external damage costs of the water filtration stage are the highest. Hence, improving the link between these two factors will reduce the value of internal resource loss, create direct economic benefits, and reduce environmental pollution. Similarly, the costs of the internal resource flow in the synthesis reaction and dry screening stages are considerably high. If the enterprise improves these links, it can reduce its internal resource loss and generate direct economic benefits without increasing social cost. Therefore, companies should increase their recycling rate of water resources by investing in new sewage treatment equipment and the latest production processes. This method will increase costs and reduce profits in the short-term, but in the long-term, it could reduce resource waste and external damage costs. The reduced costs may be greater than the reduction in revenues, thereby resulting in a net increase in profits.

\subsection{Evaluation of Hina's water resource value flow}

According to the weights of the indexes in Table 1, the comprehensive evaluation value of the value flow efficiency of a circular economy resource in iron production enterprises is 0.695 . This value was obtained by adding the weighted comprehensive scores combined with the actual index values of Hina in 2016, and the ideal values of the indicators in the ternary materials industry (we referred to the index values of advanced companies, industry averages).

Compared with the level evaluation criteria in Table 2, the comprehensive score is between 0.60 and 0.80 . Therefore, the evaluation level of resource value flow efficiency of the circular economy should be level II, which is consistent with the domestic advanced standard. Compared with the ideal value, the input index of water resources is in a relatively long cycle, and the index of water circulation is also in a good level. Meanwhile, the output index of water resources is relatively low, thereby indicating that the water resource output performance is relatively poor.

\subsection{Control of Hina's water resource value flow}

\section{(1) Optimize investment options}

This study used the preceding comprehensive analysis and research on the circulation of Hina's circular economy as bases to propose four alternative water-saving reconstruction projects for the different production stages. These projects are denoted as $b_{1}, b_{2}, b_{3}$, and $b_{4}$. Table 5 shows the comprehensive cost-efficiency of the different options.

Table 5 Comprehensive cost-efficiency of different options (unit: yuan)

\begin{tabular}{lcccc}
\hline Project & $\mathrm{b}_{1}$ & $\mathrm{~b}_{2}$ & $\mathrm{~b}_{3}$ & $\mathrm{~b}_{4}$ \\
\hline Internal economic benefits & 518946 & -406956 & 558182 & 763166 \\
External economic benefits & 111339 & 475105 & 447321 & -128362 \\
\hline
\end{tabular}

$b_{1}$ : The use of a new water-saving reaction vessel in the center of the synthesis reaction requires equipment investment of 5.46 million yuan, which would be amortized over the use life of 10 years. According to the data provided by the construction unit, the total water consumption of the synthetic reaction workshop would decrease to 176783 tons after the water-saving renovation. The rate of positive products remained unchanged, but the amount of mother liquor wastewater and ammoniacontaining waste gas generated would decrease.

Table 4 Two-dimensional accounting summary of Hina's water resource internal and external cost

\begin{tabular}{|c|c|c|c|c|c|}
\hline \multirow[t]{2}{*}{ Stage } & \multicolumn{3}{|c|}{ Internal water loss cost } & \multicolumn{2}{|c|}{ External environmental damage cost } \\
\hline & Item & Value flow cost (yuan) & Proportion & Value flow cost (yuan) & Proportion \\
\hline \multirow{3}{*}{$\begin{array}{l}\text { Synthesis } \\
\text { reaction }\end{array}$} & Positive products & 3671931 & $77.90 \%$ & 523865 & $32.92 \%$ \\
\hline & Negative products & 1041715 & $22.10 \%$ & & \\
\hline & Total & 4713646 & $100 \%$ & & \\
\hline \multirow[t]{3}{*}{ Water filtration } & Positive products & 4963938 & $57.07 \%$ & 917713 & $57.66 \%$ \\
\hline & Negative products & 3734043 & $42.93 \%$ & & \\
\hline & Total & 8697981 & $100 \%$ & & \\
\hline \multirow[t]{3}{*}{ Dry sieving } & Positive products & 3409800 & $68.69 \%$ & 149967 & $9.42 \%$ \\
\hline & Negative products & 1554241 & $31.31 \% \%$ & & \\
\hline & Total & 4964041 & $100 \%$ & & \\
\hline
\end{tabular}


$b_{2}$ : In water filtration, the use of new circulating water treatment technology would enable the company to use only recycled water in the production process. This technology would require an equipment investment of 3.9 million yuan, which would be amortized over the use life of 10 years. Moreover, the technology increases the cost of circulating water to 1.924 yuan/ton.

$b_{3}$ : A new type of semi-enclosed water circulation process could be adopted in the center of the water filtration. After the process is adopted, fresh water in the water filtration system would be substantially reduced, and the amount of wastewater generated would also be considerably reduced. The technology requires an investment of 9.62 million yuan to implement the transformation, which would be amortized over the 10-year use period.

$\mathrm{b}_{4}$ : A high-pressure ammonia removal process could be used for Hina's wastewater treatment system. The data indicated that the cost of wastewater treatment would be reduced to 1.43 yuan/ton, and approximately 195 tons of ammonia water would also be recovered. However, the cost of the external environmental damage would be increased. Overall, this technology requires an investment of 1.56 million yuan to implement the transformation, which would be amortized over the use period of 10 years.

(2) Provide targets and its polarity

Table 3 shows that each target value and polarity can be determined, and the effectiveness of the aforementioned scheme can be analyzed accordingly.

(3) Assign effect samples to different targets

The various optimization projects established by Hina were brought into the target system of the optimization model, and the target effect sample data of different projects was obtained (Table 6).

(4) Calculate the effect measure for targets of different polarities

The polarity of each indicator indicated that the effect measurement formula can be used for calculation. How- ever, a few special indicators will have negative values, thereby showing contrasts with the operating rules of the gray situation method. Therefore, this study uniformly set negative results to 0 . Table 7 shows the effect measure of each target value.

(5) Calculate comprehensive performance measures and make optimal decisions

Lastly, we calculated the comprehensive effect measurement according to Eq. (7), where $R_{11}^{\Sigma}=0.5771, R_{12}^{\Sigma}=$ $0.7056, R_{13}^{\Sigma}=0.9083$, and $R_{14}^{\Sigma}=0.7041$. In terms of the transformation effect, we found that the improvement project $b_{3}$ of the water filtration system using the new semienclosed water cycle process would have the best effect. First, the program would enable the internal water resource consumption of Hina to be effectively controlled. The amount of ammonia-nitrogen emissions into the external environment would be substantially reduced, and the overall utility would be effectively improved. Second, project $b_{3}$ requires relatively large input resources. Considering the cash flow and strategic development of the enterprise, project $b_{2}$ is also a good investment choice when combined with the actual situation of the company. The reason is that project $b_{2}$ requires the smallest amount of capital investment. Although it would increase the internal water resource costs of the enterprise to a certain extent, it has evident environmental protection effects, which would considerably enhance the sense of corporate social responsibility. The effects of project $b_{1}$ on reducing water resource consumption and external environmental damage are weaker than those of project $b_{3}$. Hence, this study excluded project $b_{1}$. Project $b_{4}$ focuses on the reduction of water resource consumption, which increases the damage to the external environment, and has the highest annual operating cost and high cash flow pressure. Thus, this project was also excluded.

The specific application of the aforementioned scheme can be implemented in combination with the PDCA (plando-check-action) cycle management. Doing so can form a

Table 6 Target effects of the different reconstruction projects in Hina

\begin{tabular}{|c|c|c|c|c|c|}
\hline & Projects & $\mathrm{b}_{1}$ & $\mathrm{~b}_{2}$ & $b_{3}$ & $\mathrm{~b}_{4}$ \\
\hline \multirow{4}{*}{$\begin{array}{l}\text { Comprehensive } \\
\text { economic utility } \\
\text { indicators A }\end{array}$} & A1: Total investment (yuan) & 5460000 & 3900000 & 9620000 & 1560000 \\
\hline & A2: Economic benefits (yuan) & 518946 & -406956 & 558182 & 763166 \\
\hline & A3: Annual operating cost (yuan) & 273127 & 27307 & 1740172 & 280319 \\
\hline & A4: Added value output efficiency & 0 & 0.24 & 0 & 1.56 \\
\hline \multirow{4}{*}{$\begin{array}{l}\text { Resource flow } \\
\text { indicators B }\end{array}$} & B1: Water resource cost loss rate $(\%)$ & 60.42 & 45.63 & 40.35 & 64.32 \\
\hline & B2: Water recycling rate $(\%)$ & 72.64 & 84.62 & 88.65 & 67.52 \\
\hline & B3: Change rate of wastewater treatment cost (\%) & -10.15 & 0 & -48.75 & -34.95 \\
\hline & B4: Change rate of internal resource value flow (\%) & -7.60 & 6.59 & -8.69 & -9.53 \\
\hline \multirow{4}{*}{$\begin{array}{l}\text { Social environmental } \\
\text { benefit indicators C }\end{array}$} & C1: Change rate of ammonia nitride emissions (\%) & -16.50 & -35.60 & -58.69 & -19.65 \\
\hline & $\mathrm{C} 2$ : Change rate of exhaust gas damage value (\%) & -0.94 & -31.00 & -1.96 & 45.63 \\
\hline & C3: Change rate of external damage per unit output (\%) & -7.00 & -29.85 & -28.11 & 8.07 \\
\hline & C4: Change rate of wastewater discharge (\%) & -39.15 & -46.85 & -55.63 & 0 \\
\hline
\end{tabular}


Table 7 Performance measurement of the different reconstruction projects in Hina

\begin{tabular}{|c|c|c|c|c|c|}
\hline & Projects & $\mathrm{b}_{1}$ & $\mathrm{~b}_{2}$ & $\mathrm{~b}_{3}$ & $\mathrm{~b}_{4}$ \\
\hline \multirow{4}{*}{$\begin{array}{l}\text { Comprehensive } \\
\text { economic utility } \\
\text { indicators A }\end{array}$} & A1: Total investment & 0.71 & 1.00 & 0.41 & 0.25 \\
\hline & A2: Economic benefits & 0.33 & 0 & 0.35 & 1.00 \\
\hline & A3: Annual operating cost & 0.10 & 1.00 & 0.02 & 0.10 \\
\hline & A4: Added value output efficiency & 0 & 0.15 & 0 & 1.00 \\
\hline \multirow{4}{*}{$\begin{array}{l}\text { Resource flow } \\
\text { indicators B }\end{array}$} & B1: Water resource cost loss rate & 0.67 & 0.88 & 1.00 & 0.63 \\
\hline & B2: Water recycling rate & 0.82 & 0.95 & 1.00 & 0.76 \\
\hline & B3: Change rate of wastewater treatment cost & 0.21 & 0 & 1.00 & 0.74 \\
\hline & B4: Change rate of internal resource value flow & 0.80 & 0 & 0.91 & 1.00 \\
\hline \multirow{4}{*}{$\begin{array}{l}\text { Social environmental } \\
\text { benefit indicators } C\end{array}$} & $\mathrm{C} 1$ : Change rate of ammonia nitride emissions & 0.28 & 0.61 & 1.00 & 0.33 \\
\hline & $\mathrm{C} 2$ : Change rate of exhaust gas damage value & 0.03 & 1.00 & 0.06 & 0 \\
\hline & C3: Change rate of external damage per unit output & 0.23 & 1.00 & 0.94 & 0 \\
\hline & C4: Change rate of wastewater discharge & 0.70 & 0.84 & 1.00 & 0 \\
\hline
\end{tabular}

unique decision-making optimization application mode for Hina's resource value flow analysis.

1) Planning and arrangement. The circular economy development model indicated that Hina should adjust and optimize the industrial structure to establish a circular economy production system.

2) Doing and calculating. The costs are separately collected and distributed according to the three production stages of Hina. Thereafter, the cost of positive and negative products can be calculated from the loss and damage costs of each production stage.

3 ) Checking and decision-making. The previous analysis indicated that project $b_{3}$ is selected.

4) Action and continuous improvement. Hina's water resources value transfer efficiency has achieved substantial results after the improvement, and the negative environmental impact has been significantly reduced. Therefore, Hina can summarize its experience to develop standards, thereby enabling it to solve emerging problems through the PDCA cycle management.

\section{Conclusions}

Theoretically, this study used the structural characteristics and trends of the analysis of a circular economy resource flow in the ternary materials industry as bases to construct an intrinsic coupling mechanism of "resource flow-value flow". Through the combination of the external environmental damage value and the internal resource value flow of waste, the value of the effective use of resources and discarded losses can be determined to diagnose the potential for improvement. In the concrete construction of the optimization model of circular economy value flow, the gray situation decision model is adopted and the weight is determined by AHP, thereby enriching the research in the field of value flow.
In practice, this research proposed optimization ideas for water resource flow against the background of a circular economy using the production characteristics of the Hina company. The circulation economic value analysis method can effectively display the value flow and amount in the process of water resource flow, thereby providing guidance and suggestions to enterprises for optimizing the flow of water resources. The entire optimization system is based on the 3R principle of "reduction, reuse, and recycling", and is characterized by "low consumption, low emission and high efficiency". This system focuses on the efficient use and recycling of resources, and the improvement of social and environmental benefits. The application of the entire optimization system satisfied Hina's requirements for an economic growth model and its goal of sustainable development. Our findings have guiding significance for the water-saving and consumption reduction decision of the ternary materials industry. In addition, these results are beneficial in promoting the green transformation and upgrading of the industry. However, the specific input value of cost should be changed according to the actual situation of enterprises under the condition that the overall scale is fixed.

This study has certain shortcomings that may be addressed in future research. It fails to provide an indepth analysis of the related derivative issues in the followup study of Hina's optimization, and it does not further expand the group level to industrial parks to discuss the development model of a circular economy. For example, we should consider the possibility of designing a circular economic value flow decision-making optimization system that is applicable to Hina's upstream and downstream activities at the park level. Accordingly, this possible system can be used to meet the integration needs of practical applications. Lastly, research on the optimization system of circular economic value flow needs further evolution and innovation. 
Open Access This article is licensed under a Creative Commons Attribution 4.0 International License, which permits use, sharing, adaptation, distribution and reproduction in any medium or format, as long as you give appropriate credit to the original author(s) and the source, provide a link to the Creative Commons licence, and indicate if changes were made.

The images or other third party material in this article are included in the article's Creative Commons licence, unless indicated otherwise in a credit line to the material. If material is not included in the article's Creative Commons licence and your intended use is not permitted by statutory regulation or exceeds the permitted use, you will need to obtain permission directly from the copyright holder. To view a copy of this licence, visit http:// creativecommons.org/licenses/by/4.0/.

\section{References}

Bouzon M, Govindan K, Rodriguez C M T (2018). Evaluating barriers for reverse logistics implementation under a multiple stakeholders' perspective analysis using grey decision-making approach. Resources, Conservation and Recycling, 128: 315-335

Burritt R L, Christ K L, Omori A (2016). Drivers of corporate waterrelated disclosure: Evidence from Japan. Journal of Cleaner Production, 129: 65-74

Burritt R L, Schaltegger S, Zvezdov D (2011). Carbon management accounting: Explaining practice in leading German companies. Australian Accounting Review, 21(1): 80-98

Busch T, Liedtke C, Beucker S (2005). The concept of corporate resource efficiency accounting - A case study in the electronic industry. In: Schaltegger S, Bennett M, Burritt R, eds. Sustainability Accounting and Reporting. Berlin: Springer, 109-128

Cassimon D, Engelen P, van Liedekerke L (2016). When do firms invest in corporate social responsibility? A real option framework. Journal of Business Ethics, 137(1): 15-29

Çelikbilek Y, Tüysüz F (2016). An integrated grey based multi-criteria decision-making approach for the evaluation of renewable energy sources. Energy, 115: 1246-1258

Chapagain A K, Tickner D (2012). Water footprint: Help or hindrance? Water Alternatives, 5(3): 563-581

Christ K L, Burritt R L (2017). Water management accounting: A framework for corporate practice. Journal of Cleaner Production, 152: $379-386$

Collet L, Ruelland D, Estupina V B, Dezetter A, Servat E (2015). Water supply sustainability and adaptation strategies under anthropogenic and climatic changes of a meso-scale Mediterranean catchment. Science of the Total Environment, 536: 589-602

Ding X H, He J H, Wang L Y (2018). Inter-provincial water resource utilization efficiency and its driving factors considering undesirable outputs: Based on SE-SBM and Tobit model. China Population, Resources and Environment, 28(1): 157-164 (in Chinese)

Gao C K, Zhang M H, Wei Y X, Na H M, Fang K J (2016). Construction and analysis of "water carrier" and "water value" in the iron and steel production. Journal of Cleaner Production, 139: 540-547

Giuliani E (2016). Human rights and corporate social responsibility in developing countries' industrial clusters. Journal of Business Ethics, 133(1): 39-54

Hazelton J (2014). Corporate water accountability - The role of water labels given non-fungible extractions. Pacific Accounting Review, 26 $(1 / 2): 8-27$
Herzig C, Viere T, Schaltegger S, Burritt R L (2013). Environmental Management Accounting: Case Studies of South-East Asian Companies. London: Routledge

Hu W, Long Q H, Qian M, Liu G B (2014). Determination of evaluation index system weight for enterprises wastewater treatment based on AHP. Environmental Pollution \& Control, 36(2): 88-91, 95 (in Chinese)

Jasch C M (2008). Environmental and Material Flow Cost Accounting: Principles and Procedures. Springer

Jones P, Hillier D, Comfort D (2015). Water stewardship and corporate sustainability: A case study of reputation management in the food and drinks industry. Journal of Public Affairs, 15(1): 116-126

Khalil N, Kamaruzzaman S N, Baharum M R (2016). Ranking the indicators of building performance and the users' risk via Analytical Hierarchy Process (AHP): Case of Malaysia. Ecological Indicators, 71: 567-576

Li D Y, Huang M, Ren S G, Chen X H, Ning L T (2016). Environmental legitimacy, green innovation, and corporate carbon disclosure: Evidence from CDP China 100. Journal of Business Ethics, 150: 1089-1104

Martinez F (2015). A three-dimensional conceptual framework of corporate water responsibility. Organization \& Environment, 28(2): 137-159

Nakajima M, Kimura A, Wagner B (2015). Introduction of Material Flow Cost Accounting (MFCA) to the supply chain: A questionnaire study on the challenges of constructing a low-carbon supply chain to promote resource efficiency. Journal of Cleaner Production, 108: 1302-1309

Park Y W, Hong P, Roh J J (2013). Supply chain lessons from the catastrophic natural disaster in Japan. Business Horizons, 56(1): 7585

Pitchipoo P, Venkumar P, Rajakarunakaran S (2013). Modeling and development of a decision support system for supplier selection in the process industry. Journal of Industrial Engineering International, 9 (1): 23

Prox M (2015). Material flow cost accounting extended to the supply chain-Challenges, benefits and links to life cycle engineering. Procedia CIRP, 29: 486-491

Qiu Y, Shaukat A, Tharyan R (2016). Environmental and social disclosures: Link with corporate financial performance. British Accounting Review, 48(1): 102-116

Signori S, Bodino G A (2013). Water management and accounting: Remarks and new insights from an accountability perspective. In: Songini L, Pistoni A, Herzig C, eds. Accounting and Control for Sustainability (Studies in Managerial and Financial Accounting, vol. 26). Bingley: Emerald Group Publishing Ltd., 115-161

Sindhu S, Nehra V, Luthra S (2017). Investigation of feasibility study of solar farms deployment using hybrid AHP-TOPSIS analysis: Case study of India. Renewable \& Sustainable Energy Reviews, 73: 496511

Song X, Li Z (2012). Modified index system for eco-efficiency evaluation of circular economy in economy in coal mining area based on network flow analysis. Journal of Convergence Information Technology, 7(13): 1-9

Sulong F, Sulaiman M, Norhayati M A (2015). Material Flow Cost Accounting (MFCA) enablers and barriers: The case of a Malaysian 
small- and medium-sized enterprise (SME). Journal of Cleaner Production, 108: 1365-1374

Wan Y K, Ng R T L, Ng D K S, Tan R R (2015). Material Flow Cost Accounting (MFCA)-based approach for prioritisation of waste recovery. Journal of Cleaner Production, 107: 602-614

Wei Y H (2017). Method research of construction engineering project investment project preference based on grey situation decisionmaking theory. Journal of Jilin Jianzhu University, 34(5): 104-108 (in Chinese)

Xiao X, Jin Y L (2008). Discussion on construction of resource value flow accounting - By way of recycling economy in process-based manufacturing enterprises. Journal of Finance and Economics, (10): 122-132 (in Chinese)

Xiao X, Liu S H (2014). Environmental management accounting research based on "elements flow-value flow" analysis. Accounting Research, (3): 79-87, 96 (in Chinese)

Xiao X, Xiong F (2010). Theory and methodology system of resource value flow based on recycling economy. Systems Engineering, 28 (12): 64-68 (in Chinese)

Xiao X, Zeng H X, Li S H (2017). Study on "material flow-value floworganization" three-dimensional model of environmental management accounting. Accounting Research, (1): 15-22, 95 (in Chinese)
Xiong F, Xiao X (2014). Performance measurement of circular economy of iron and steel enterprises based on value flow. Environmental Pollution \& Control, 36(5): 13-18, 23 (in Chinese)

Xiong F, Xiao X, Chen X H, Zhou Z F (2015). Path optimization of Chinese aluminum corporation for a circular economy strategy based on a resource value flow model: A case study of China LCO. Environmental Engineering and Management Journal, 14(8): 19231932

Yang H F (2006). Evaluation index system of enterprises competitiveness based on circular economy. Systems Engineering, 24(11): 79-84 (in Chinese)

Zheng L, Xiao X (2010). Study on control decision model of resource flow cost accounting. The Theory and Practice of Finance and Economics, 31(1): 57-61 (in Chinese)

Zhou Z F, Liu L M (2017). Research on the environmental protection investment decision of thermal power enterprises based on the transfer of resource value. Science \& Technology Progress and Policy, 34(9): 114-120 (in Chinese)

Zhou Z F, Zhang L Y, Ou J (2018). Research on the optimization of the circular economy value flow in process manufacturing enterprises-Taking papermaking companies as an example. Accounting and Finance, 175(5): 67-73 (in Chinese) 